\title{
Motivated thinkers and the mistakes they make: The goals underlying social cognitions and their consequences for achievement
}

\section{Citation}

Gehlbach, Hunter, and Maureen E. Brinkworth. 2008. Motivated thinkers and the mistakes they make: The goals underlying social cognitions and their consequences for achievement. Elsevier . doi:10.1016/S0749-7423(08)15004-X. http://dx.doi.org/10.1016/S0749-7423(08)15004-X.

\section{Published Version}

doi:10.1016/S0749-7423(08)15004-X

\section{Permanent link}

http://nrs.harvard.edu/urn-3:HUL.InstRepos:11384949

\section{Terms of Use}

This article was downloaded from Harvard University's DASH repository, and is made available under the terms and conditions applicable to Other Posted Material, as set forth at http:// nrs.harvard.edu/urn-3:HUL.InstRepos:dash.current.terms-of-use\#LAA

\section{Share Your Story}

The Harvard community has made this article openly available.

Please share how this access benefits you. Submit a story.

\section{Accessibility}


Running Head: MOTIVATED THINKERS

Motivated thinkers and the mistakes they make:

The goals underlying social cognitions and their consequences for achievement

Hunter Gehlbach and Maureen E. Brinkworth

Harvard University 
Social psychologists have spent many long hours contemplating the terrain where motivation intersects with thinking. Specifically, the field of social cognition has developed a rich literature describing how we perceive our social worlds and the ways in which we might be motivated to think about those social worlds (Fiske, 1995). In particular, these scholars have documented numerous flaws resulting from the goals that motivate our social thinking. These errors and biases seem likely to pose serious problems in educational and achievement contexts. In spite of the extensive literature in this area, social cognition scholars have rarely focused on these settings. Thus, great potential exists for applying social psychological research on the goals behind our social cognitions to educational contexts.

In this chapter, we review research on social cognition and suggest ways that it might illuminate our understanding of and enhance our social interactions in achievement settings. We focus particularly on flaws in our social cognitions and, borrowing Ross’ (1981) conception of the lay person as an intuitive scientist, what the implications of these flaws are for us as social perceivers. We then propose that there are three basic goals that influence our social cognitions. After discussing each, we examine the implications this conceptualization of social cognition in achievement settings. Primarily, we address educational settings, focusing on students and teachers. However, we suspect that parallel implications may exist for other achievement contexts such as work or athletics.

\section{The goals underlying our social cognitions}

Fiske (1995) defines social cognition as, "the process by which people think about and make sense of people” (p. 151). As perceivers, we typically make sense of others quickly. Yet, as targets of others' social perceptions, we feel that our thoughts, feelings, motivations, and behaviors are immensely complex for others to accurately understand. Although we are often surprisingly accurate in our first impressions about complex others (Ambady \& Rosenthal, 1993), we also make mistakes frequently. An illustrious research tradition within social cognition has brought to light many of the errors we make in our efforts to understand the social world around us. Although few of these mistakes are conscious, a great many of them are motivated in the sense that these cognitions help people pursue different goals. For example, some students may believe that their teacher calls on them only when they do not know the answer. Naturally, they perceive this to be unfair and often develop increasing antipathy towards their teacher. In other words, these students observe their teachers' actions and develop a social 
cognition (i.e., an interpretation) based on these observations. Even when there is ample evidence to the contrary, these students may be motivated to maintain this cognition for a variety of reasons. They may be positively reinforced by friends when they complain about their unfair teacher; they may find that this belief helps them to explain away poor grades in the class; or they may maintain this belief in the service of convincing their parents that a particular subject is really not for them.

As alluded to previously, an important characteristic of the goals behind social cognitions is that they are not always conscious. If these same students were asked about their teacher picking on them unfairly, they would explain with great conviction the incontestable veracity of their belief. (With the benefits of selective recall, they may even provide compelling evidence to defend their assertion.) They may also articulate their fondness for interacting with friends, that they are not doing as well in this class, or that they wish that their parents were less concerned with their performance in this particular subject. However, it seems unlikely that they would consciously connect their belief about being picked on with these goals underlying that cognition. On the other hand, some instances of motivated thinking are clearly conscious. Athletes are motivated to regularly and consciously convince themselves of their superiority over their opponents.

We should also note that many social cognitions are not motivated at all. Frequently, we infer the mental states of others without being intentional or goal directed. Without trying, we might spontaneously infer that somebody is happy or amused by observing the smile on their face. These observations and inferences tend to be relatively automatic in the sense that they happen quickly, require negligible effort, and probably are not retained in memory for any length of time. In this way, they may resemble the precognitive affective judgments described by Zajonc (1980).

As a final note, the goals that underlie our social cognitions, should be distinguished from habits of mind, propensities, or thinking dispositions (Perkins, Tishman, Ritchhart, Donis, \& Andrade, 2000). According to Perkins et al. (2000), thinking dispositions concern how people are disposed to enact whatever thought-related abilities that they have. Thus, a tendency to be close-minded, curious, or reflective would constitute a thinking disposition. Kruglanski and his colleagues’ work on “need for closure” (e.g., Dijksterhuis, van Knippenberg, Kruglanski, \& Schaper, 1996) provides another example. These dispositions are comprised of some minimum 
element of ability, the inclination to enact that ability, and the sensitivity to notice situations where that ability might be enacted (Perkins et al., 2000). Although these dispositions are likely to play a role in the goals that underlie our social cognitions, they are more akin to personality traits. In other words, thinking dispositions might explain general trends in one's thinking (and behavior) across many situations over time. The present chapter instead develops a framework to help understand the goals that direct our social cognitions in individual situations. We hypothesize these goals to be so fundamental that in any given situation at least one of them will aptly characterize our social cognitions, regardless of our general thinking dispositions.

With these clarifications in mind, we hypothesize that three basic goals underlie people's social cognitions. (1) Accurate understanding: People are motivated to think in ways that will facilitate their understanding of themselves and others in their social world. This primary motive can be challenged, interrupted, or superseded by two additional goals. (2) Enhancing one's sense of self: People are motivated to think in ways that enhance or maintain their sense of self. In other words, people are likely to preferentially recall, retain, and believe cognitions that (directly or indirectly) flatter the self or help to maintain a positive self-image. (3) Efficiency: People are motivated to think efficiently. On the one hand, we are motivated to economically process the vast amounts of information in our social environments, but we are also "cognitive misers” who frequently strive to avoid hard thinking (Fiske, 1995).

In sum, our overarching goal is to accurately understand others, but this goal may be undermined by competing goals to maintain our sense of self or to conserve mental effort. To be sure, these are not mutually exclusive goals. Many of our efficient mental shortcuts are intended to produce accurate understandings and, coincidentally, happen to be flattering to ourselves. These three goals can work in concert, independently, in opposition to one another. To evaluate this idea that all social cognitions can be conceptualized as one of these three goals, we examine each goal in turn and highlight some of the mistakes associated with each.

\section{Goal \#1: Accurate understanding of ourselves and others}

In order to effectively navigate our social worlds, we need to better understand those who inhabit it (Heider, 1958b). Thus, as a primary, fundamental goal - our default setting - we try to accurately understand others in our social environment (Kunda, 1990). Accurately perceiving who is doing what and why is essential for guiding our behavior. Ross (1981) has described people trying to make sense out of their social environments as “intuitive scientists.” According 
to Ross, we pursue several tasks in an effort to understand our social context: perceiving and encoding information about a given situation (often through observation); determining the extent to which our sample of data might generalize to other situations; looking for correlational or causal patterns in the data; and summarizing that information into a theory that we can test and revise. From these lay theories, we can make predictions that allow us to negotiate our social worlds proactively and strategically.

To illustrate this process, imagine a new student joining a class part-way through the year. She will be motivated to understand what her new peers are like, how they interact with each other, and what their working styles are like. As part of this data collection process, she may interact with some of her peers to learn their norms and typical response patterns. If she asks classmates to borrow lunch money, presumably some will assent, and others will refuse her. With each request and interaction, she will have to decide how representative each successful loan or rejection is and perhaps weight it correspondingly. As she collects these data, she can begin to draw conclusions about which norms are associated with or causally related to the different outcomes. Perhaps she obtains lunch money more frequently when she intimidates her classmates, but she simultaneously loses friends. Throughout this process she will construct tentative theories that allow her to predict how her behaviors will be received by others and how others will interact with her. As these predictions are supported or disconfirmed, she may or may not choose to revise the underlying theories.

Presumably the more accurate our theories and predictions are about the others in our social environment, the more effective our behaviors will be. To maximize our effectiveness, we are fundamentally motivated to accurately understand those in our social surroundings. Although this goal is basic, there are no guarantees that we will achieve accuracy in our thoughts and inferences about those in our social environments (Kunda, 1990). Quite often, we choose inept strategies, are subject to bias, and make mistakes. In this section, we illustrate four potentially problematic tendencies in our thinking when we put on our "intuitive scientist" thinking caps and attempt to make sense out of others in our social worlds. Although some of the research we summarize describes non-social cognitions, all of the fundamental biases and problems described do apply to social thinking.

Understanding what we perceive 
Although we are generally competent at perceiving and encoding data gathered from others and ourselves in social settings, we are imperfect. One common bias that we have is described by Tversky and Kahneman (1974) as the availability heuristic - a tendency to judge probabilities or likelihoods of events based upon their accessibility in our minds. Specifically, those thoughts that are more available to us are viewed as more likely to occur. In one illustration of this principle, Tversky and Kahneman showed that people mistakenly presume that more words in English begin with "k" or "r" than have "k" or "r" as their third letter (e.g., kite/take or red/car). They attribute this erroneous assumption to people usually arriving at an answer by thinking of examples of both types of words. However, people fail to account for how much easier it is to search through one's vocabulary using first letters rather than third letters. The first letters of words are simply more available to us, so naturally we generate more examples of words beginning with " $k$ " or " $r$ ".

Although the illustration in this experiment is trivial, the implications for classrooms are not. In most classrooms, teachers focus more of their attention on boys than girls in spite of thinking that they are allocating their attention evenly (Beaman, Wheldall, \& Kemp, 2006). Because boys cause trouble in more visible ways, they are likely to be more available in teachers' minds. As a result, teachers who strive to accurately understand whether they are deploying their attention fairly may actually attend to boys disproportionately while thinking that they are being equitable. In this way, teachers may err in their goal to accurately observe their social world.

\section{Understanding our sample}

Tversky and Kahneman (1974) identify a second heuristic that creates potential problems for us. As we pursue our goal to accurately understand those in our social worlds, we try to understand what our sample of data is like. Of particular importance, we try to determine whether the specific data that we have collected is idiosyncratic or generalizable. When engaging in this task we often rely on the representativeness heuristic. Tversky and Kahneman describe this judgmental guideline as an assessment, "in which probabilities are evaluated by the degree to which A is representative of B, that is, by the degree to which A resembles B” (1974, p. 1124). In other words, we often confuse representativeness with similarity.

They illustrate this heuristic through several different studies. In one, they show that people ignore baseline rates and prior probabilities because they are swayed by the 
representativeness of a description. For example, after reading a description of someone who fits multiple stereotypes of a librarian, people are then asked to determine the person's profession. In deciding, people routinely ignore the fact that being a librarian is a relatively uncommon.

In a school context, we can again see how serious problems might result from the representativeness heuristic in spite of our goal to accurately perceive others in our social environment. Teachers who encounter immigrant students who struggle to articulate their thoughts in English might make negative inferences about the capabilities of these students. In terms of their diction, these students may sound similar to less capable, native English-speaking peers. However, this inference ignores the baseline rate that almost nobody sounds eloquent in a foreign language that they are still mastering. Thus, these teachers have confused the foreign students' sounding similar to their less capable classmates with the extent to which articulateness is representative of academic capacity.

\section{Understanding correlations and causes}

In trying to accurately understand our social contexts, we are especially interested in discerning who or what is responsible for certain outcomes (Heider, 1958a). As observers of these contexts, we are particularly sensitive to and observant of patterns of co-occurrence. However, while we are quite good at observing some patterns (e.g., those that are salient or available to us), we fail to identify others (e.g., those that run counter to our intuition). Furthermore, we even identify patterns of co-occurrences that do not exist. This "illusory correlation” is our tendency to detect associations between events that are actually unrelated (Chapman, 1967).

In addition to this process of detecting covariation, we are particularly motivated to detect causal relationships. Ross, Amabile, and Steinmetz (1977) found evidence of a systematic error that we make when we try to assess why people behave as they do. According to the “fundamental attribution error,” we tend to overemphasize the role that a person's dispositions play in explaining their behavior while underestimating the relative influence of the situation. Ross and his colleagues illustrated this principle by staging a quiz show in which two participants were randomly selected to play the role of either the questioner or the answerer. The questioner asked a series of "challenging, but not impossible" questions to the other contestant. Because they could select questions exclusively from areas of their unique expertise, the questioners enjoyed a huge advantage based on their role. At the end of the questioning, the 
contestants provided intelligence ratings for themselves and the other participant (compared to other students at their institution). The answerers rated the questioners' intelligence at the $67^{\text {th }}$ percentile. Meanwhile, the questioners, who were in a position to realize their role-conferred advantage, rated themselves only at the $54^{\text {th }}$ percentile. The authors interpreted these findings as evidence that we tend to overemphasize the impact of dispositional causes (e.g., the questioner was quite intelligent) relative to situational causes (e.g., the game made it much easier to be the questioner).

These errors in detecting patterns and assessing causality from those patterns can create serious problems in school settings. For example, if students detect an illusory association that a certain group of their peers receives preferential treatment from their teacher, they may well make the dispositional attribution that their teacher is prejudiced. This type of attribution can poison a classroom climate and impede learning.

\section{Understanding our theories}

Perhaps our most critical task as intuitive scientists is to develop and revise theories that will allow us to predict events in our social environments so that we can adapt to them. Our best theories simplify and increase the utility of the data that we have observed, generalize beyond the sample data, and illuminate correlational and causal relationships. Most importantly, our theories should help us achieve the goal of accurately perceiving those in our social environment. For the most part, our theories probably do facilitate accurate social cognitions. However, these theories are also subject to problematic biases.

One particularly problematic bias is that we selectively seek out evidence that confirms the theories that we develop (Wason, 1960). In other words, we selectively attend to, encode, store, and retrieve information that is congruent with our notions of how people in our social environments function. The inverse of this confirmation bias is similarly problematic - we tend to disregard or discredit evidence that might disconfirm our theories.

Rosenthal's work on self-fulfilling prophecies in the classroom presents what might be viewed as an extreme example of confirmation bias (Rosenthal, 2002). In the classic “Pygmalion” experiment (Rosenthal \& Jacobson, 1968), teachers are led to believe that certain students are poised to make a big academic leap during the current year. In other words, the experimenters provide them with a theory that the teachers can then seek to confirm (or disprove) through interacting with their students throughout the remainder of the year. Results 
of the original and many follow-up studies (e.g., Jussim \& Eccles, 1992) indicate that teachers expectations do influence student performance. According to Rosenthal (2002), these teachers create a warmer climate for these students, teach them more, give them greater opportunities to respond, and provide them with more differentiated feedback. The result of teachers confirming the theories they have adopted in these experiments is that these students did indeed perform better than the students in the control group. Whether teachers are developing and confirming theories about their students or vice-versa, the "Pygmalion" studies show the effects of confirmation bias in the classroom, even when teachers and students are motivated to accurately perceive one another.

In sum, we posit that, as social perceivers we are fundamentally motivated to accurately perceive the situations in which we find ourselves. However, this goal alone provides no guarantee that we will achieve accuracy in our perceptions. As intuitive scientists, we collect data samples, assess the generalizability of those samples, find correlational and causal associations, and develop theories that help us navigate our social worlds. However, unwitting, unmotivated mistakes in our thinking and biases in our processing can inhibit this fundamental goal of accuracy. To make matters worse, there are often competing goals influencing our social cognitions.

\section{Goal \#2: Enhancing one's sense of self}

One of the main goals that disrupts our efforts to accurately perceive our social world is the goal to maintain or bolster our sense of self (Dunning, 1999). Social psychologists have examined a multitude of ways in which people go to great lengths to preserve their self-esteem and their self-concept. As in the previous section, we will review a few illustrative examples rather than cataloguing the universe of strategies that people employ to maintain or enhance their sense of self. Specifically, we will examine the ways in which we maintain self-serving biases, engage in naïve realism, and strive to maintain a consistent self-concept.

\section{Self-serving biases}

We have developed a number of strategies to facilitate our goal to see ourselves in a flattering light. Among the best known, are the ways that we value certain traits, and how we compare ourselves to others on those traits. Dunning (1999) reviews several of these findings. In one strategy, when describing attributes of desirable personal qualities, we tend to emphasize attributes we think we possess. For example, those who view themselves as ambitious and 
independent might view those attributes as important to good leadership; meanwhile, those who view themselves as caring and people-oriented might view those traits as central to being a good leader. As a second strategy, Dunning indicates that we tend to think of ourselves as above average on most positive attributes such as being sensible, idealistic, or disciplined. Conversely, we view ourselves as below average on negative traits. As a third technique, we rate people who we view as similar to ourselves more favorably than those who are dissimilar.

While this self-serving view of the world may play a role in mitigating stress, anxiety, and depression (Arkin, Appelman, \& Burger, 1980; Greenberg, Pyszczynski, Burling, \& Tibbs, 1992), this goal to see oneself positively can also be problematic. According to Kruger (1999), those who are the least proficient in certain domains are the most deluded in their selfassessments. On tests of humor, logic, and grammar, people scoring in the $12^{\text {th }}$ percentile on skills rated themselves at the $62^{\text {nd }}$ percentile on average. Kruger explains that having low skills in a domain may signal diminished metacognitive capability in that domain. This lack of metacognitive ability inhibits one’s effectiveness in self-assessing those skills.

Although we do not know the extent to which these findings generalize from the laboratory to the classroom, the implications are unsettling. Those students with the worst study skills may think that their skills are well above average. They may not know enough about what good studying looks like to accurately reflect on and assess their skill level. Consequently, they probably do not perceive a need to improve those skills. It's also conceivable that the worst behaved students may think that their behavior is better than average, thus mitigating a need to improve their behavior. At the more general level of our self-serving biases, it may be that students (or teachers for that matter) might be motivated to discount or dismiss constructive criticism that might threaten their self-esteem. If true, this resistance to constructive criticism poses a barrier to learning and warrants substantial attention from researchers. In classrooms, for example, students who perceive themselves as excellent writers may simply ignore their teacher's suggestions for improving clarity, arguing that they have made stylistic innovations rather than mistakes.

Naïve realism

A second domain of goals that enhance our sense of self includes those that guide our subjective impressions of the world. Ross and Ward's (1996) theory of naïve realism suggests that we perceive the world in ways that are crucial to maintaining our sense of self. They pose 
three tenets in this theory. First, we believe that we see objective reality. Second, other rational people will share our perception of this reality. Third, if others do not share this perception, it is because they were exposed to different information, they are unwilling or unable to process the information normally, or they are biased. In sum, we believe that our perceptions and opinions of the world are basically correct; consequently, those who disagree with us must be wrong.

In support of this theory, Ross and Ward cite evidence such as the false consensus effect - a phenomenon in which people tend to believe that their opinion is normative. In an empirical demonstration of this effect, Ross and his colleagues (Ross, Greene, \& House, 1977) offered Stanford undergraduates the chance to participate in a study by walking around campus in a sandwich board whose advertisement encouraged students to "Eat at Joe’s”. Alternatively, students could turn down this offer and participate in a later study instead. After deciding whether to participate or not, students then estimated the percentage of other subjects who would agree to participate. Students who had just agreed to participate assumed that most of their peers would also agree to participate. Those who had just refused presumed that the majority of students would also refuse. In addition to assuming that our opinion is the majority opinion, Ross and Ward review evidence indicating that we perceive ourselves to be moderate and nuanced in our point of view, and we perceive those with opposing opinions as having extreme perspectives (e.g., Arabs and Israelis or Democrats and Republicans perceiving one another). Thus, we believe that we see objective reality, assume ourselves to be in the majority opinion in this view of objective reality, and tend to exaggerate our differences with the other side.

This belief that we perceive objective reality (and the other side does not) has potent implications. To get a sense of how potent, simply imagine what life would be like if we were not motivated to maintain this belief. It would be hard for us to get out of bed in the morning if we constantly doubted whether our interactions with others were really as they seemed to be.

Because this belief that we see objective reality is so important, when it is threatened, we defend it fiercely. When seen through this lens of naïve realism, it suddenly becomes much easier to see why seemingly petty classroom conflicts between students tend toward escalation rather than resolution. It also makes more sense that emotional meltdowns often result when a teacher sides with one student over another in refereeing such conflicts. At the core of many of these disagreements is a battle over whether the reality that a student (or teacher) perceives is affirmed or discredited. Thus, rather than daily conflicts of opinion that arise in schools turning 
into valuable learning opportunities, they often escalate and derail the learning process. For instance, imagine that a U.S. Government teacher, who is a Democrat, decides to present a lesson on the upcoming presidential election. During the lesson a student angrily objects to the presentation stating that she is a Republican and the teacher is clearly favoring the Democratic candidate. Both teacher and student believe that they are viewing the situation objectively. They will likely conclude that the other party must be an extremist to see it any differently. An argument may ensue, and the focus of the lesson will likely be lost.

Cognitive dissonance

A third way in which we are motivated to enhance the self is our goal to reduce feelings of cognitive dissonance. In other words, we are motivated to present and maintain an image that we are a cohesive, consistent self. In the original research on this topic, subjects performed a boring task and then were asked to lie to the next participant in the waiting room about how enjoyable the task was (Festinger, 1962). When participants were asked later for their true opinion of the task, those who were paid \$20 justified their lie much more easily than those who were paid only $\$ 1$. Results indicated that the underpaid subjects rationalized these discrepant thoughts of performing an aversive task and misrepresenting their experience by convincing themselves that they really did like the task. Evidently, this rationalization was easier than entertaining the notion that they were an inconsistent person who lied to others for the sake of making them perform the same unpleasant task they had just endured.

Numerous replications and follow-up studies of cognitive dissonance have followed. Cialdini (2001) notes a number of the seemingly absurd lengths people will go to in order to maintain consistency and not threaten their sense of self. People have agreed to post ugly billboards in their yards, endured harsh hazing rituals, and awaited UFOs for hours - all an effort to maintain cognitive consistency. From these additional studies, several important caveats have been noted in the theory of cognitive dissonance. Specifically, if we are to experience cognitive dissonance, we must feel that we have freely chosen to engage in the behavior in question and that behavior must have foreseeable negative consequences (Cooper \& Fazio, 1984). Of particular importance in the present context is Kunda’s conclusion that, “These conditions suggest that dissonance arousal requires a threat to the self: The cognition that one has knowingly chosen to engage in a bad or foolish behavior is inconsistent with a self image as a decent and intelligent person” (1990, p. 484). 
We suspect that, as students approach adolescence and tend to become more concerned with developing a stable identity (Erikson, 1968; Waterman, 1982), their goal to maintain cognitive consistency may become increasingly important. Specifically, students' efforts to project a coherent identity to their peers may increase. To the extent that they freely engage in behaviors that are congruent or incongruent with a self-image of "a good student" they are probably paving the way for similar behaviors in the future. In other words, the behaviors that students engage in at school will likely build momentum for similar behaviors in the future simply because engaging in other types of behaviors might threaten students' sense of self by potentially appearing inconsistent.

\section{Goal \#3: Efficiency}

The second group of goals that disrupts our striving to accurately perceive our social world is that we strive towards cognitive efficiency. Stated less favorably, we are "cognitive misers” who dislike putting forth more effort into our thinking than necessary (Fiske, 1995). Within person perception, two of the more commonly used cognitive labor saving strategies are categorizing/stereotyping others and anchoring and adjusting. This section describes these two basic strategies that we employ to make sense of other people.

Categorizing, stereotyping, in-groups, and out-groups

One of the most essential cognitive processes that we engage in is to group perceived stimuli into categories (Allport, 1979/1954). For the most part, this grouping process effectively simplifies the complex world around us. Although we may not wish to encounter either, having clearly defined categories for "liars" and "lions” allows us to quickly assess the threat we are facing. We can then choose which actions will be most appropriate in responding to the situation. In the case of avoiding lions, the speedier cognitive processing facilitated by categorical thinking will be especially adaptive! Although these categorization processes are normal and adaptive, when we employ them to simplify the complex world of those who we interact with, we can get ourselves into trouble.

Stereotypes refer to the beliefs we have about the attributes of other groups of people. They tend to be over-generalized, inaccurate, and resistant to change (Katz \& Braly, 1933). When we encounter new individuals in our social environment, we are inclined to automatically process them according to at least a few categories (e.g., that the person is male or female, tall or 
short, etc.). As soon as we assign some of our general knowledge about that category to the individual in question, we have engaged in stereotyping. For example, upon meeting a female who is 5'11”, we might think that she is tall (i.e., does not conform to our stereotype of the average female). On the other hand, if we also learn that she is a basketball player, we may find her height unremarkable because "tall” is congruent with our stereotype of basketball players.

Up to this point, the categorization and stereotyping processes are not particularly problematic. The difficulties emerge because we have a strong tendency to categorize people as being part of our in-group or as being members of an out-group (Devine, 1995). Our in-group could be based on any of the group memberships we hold: sex, race, political party, alma-mater, etc. Once we have made these divisions, we then begin to stereotype. We view our various ingroups as diverse but see the corresponding out-groups as relatively homogeneous. Most important, as Devine indicates, we then favor members of our in-group over the corresponding out-group (also see Turner, Brown, \& Tajfel, 1979).

These categorizations into in-groups and out-groups and the ensuing stereotyping can emerge from incredibly trivial distinctions. In an illustrative example, Galinsky and Moskowitz (2000) placed subjects into groups of under-estimators or over-estimators after they had tried to guess the number of dots on a computer screen. Even though subjects' placement into one group or the other was a product of random assignment, these subjects still favored their own group over the out-group in spite of the trivial (and fallacious) distinction that was used to divide the subjects into groups.

In a less artificial illustration, Muzafer Sherif and his colleagues demonstrated how severe discrimination and prejudice can emerge out of these perceptions of group differences (Sherif, Harvey, White, Hood, \& Sherif, 1961). In the Robbers Cave Experiment, boys at a summer camp who were assigned to one of two cabins began favoring their cabin-mates over the opposite group. Despite the groups being essentially the same because they were randomly assigned, open hostilities and fights began to erupt as soon as the experimenters introduced competitive activities. Even though the differences were purely perceptual, discrimination and prejudice between the groups were quick to foment.

In schools, much of the impact of categorization and stereotyping as it leads to prejudice and discrimination is obvious. Students who perceive themselves to be on the receiving end of discrimination or prejudice are likely to feel a diminished sense of belonging in school, will 
probably perform less well academically, and may be more likely to drop-out (Fine, 1991). However, many of the outcomes of this pervasive approach to conserving cognitive effort are more subtle. For example, most of the people and cultures studied in social studies classes are presented as out-groups so that students are likely to instinctively view them as relatively homogeneous and develop overly simplified views of their societies. In their efforts to cover vast amounts of material in ways that do not offend anybody (Loewen, 1995), social studies textbooks may reinforce this goal to think efficiently, simply, and stereotypically about others. Thus, the strategy of stereotyping can lead not only to strained relations between groups within schools, but also to diminished understanding for certain subject-matters.

\section{Anchoring and adjusting}

In addition to categorization and stereotyping, we also employ a technique known as anchoring and adjusting as we pursue our goal to efficiently make sense of others in our social world. Stereotyping may often be a reasonable approach when trying to make sense of members of an out-group who we know little about. However, when trying to make sense of other members of our in-group, we should be able to improve upon that strategy without sacrificing efficiency. Epley and his colleagues (Epley, Keysar, Van Boven, \& Gilovich, 2004) have found that people often make sense of others by using their own experience as an anchor and then making adjustments based on whatever additional knowledge they have. In other words, we often attempt to figure out other people by "putting ourselves in their shoes” and then factoring additional information into the equation as long as it is readily available. According to Epley et al. (2004), a big problem with this strategy is that our adjustments are rarely sufficient. In other words, our final assessments tend to be egocentric because, after putting ourselves in their shoes, we fail to fully account for the ways in which we differ from others.

Daniel Ames' (2004) has examined both of these strategies that we employ to save mental effort. He finds that we tend to use stereotyping strategies more frequently when we perceive others as being relatively different. However, when we perceive somebody as similar, we tend to engage in this anchoring and adjusting process (which Ames refers to as projection).

Although stereotyping probably leads to more serious problems in school settings (as described in the previous section), our tendency to make insufficient adjustments when we anchor and adjust also creates problems in educational contexts. As experts in their subject matter discipline, many teachers fail to understand their students' failure to understand. When 
teachers are intimately familiar with a concept and have understood it at a sophisticated level for years, they may struggle to take the perspective of students who have no such understanding of the concept. All too often teachers may attempt to relate to this experience by remembering back when they were trying to learn the same concept (i.e., anchoring with their own experience). Then they may try to make adjustments for different students. However, they are unlikely to sufficiently account for how they differ from their students in important factors such as prior preparation for a topic or interest in that topic.

Categorizing and stereotyping as well as anchoring and adjusting help us decipher our social environments efficiently. If we had to individually process every person that we encounter, we would quickly become overwhelmed. However, to the extent that we rely heavily on these and other labor saving strategies, we are likely to reduce the accuracy of our social perceptions and undermine our goal of accurately understanding our social world.

\section{Summary \& potential exceptions}

We have posited that three basic goals underlie our social cognitions. Most fundamentally, we are motivated to accurately perceive ourselves and others in our social environment. In striving towards this end, we often act as lay scientists trying to understand the sample of data that we perceive, determine how representative that sample is, identify correlational or causal patterns in that data, and generate theories to guide our social behavior. Although we are motivated to accurately understand our social environments we do fall victim to a range of mistakes. Overusing the availability and representativeness heuristics, committing the fundamental attribution error, and succumbing to confirmation bias are but a few of the problems that we encounter in pursuit of this basic goal. In addition, two other goals often challenge, interrupt, or supersede this goal. First, we strive to enhance (or at least maintain) our sense of self. This goal is manifested through such problems as self-serving biases, naïve realism, and rationalizing cognitive dissonance. Second, we are motivated to conserve cognitive effort. As “cognitive misers” (Fiske, 1995), we engage in categorization and stereotyping as well as anchoring and adjusting. Although often highly functional, these strategies also cause errors in our assessments of others.

The notion that these three goals can describe all of our motivated social cognitions is potentially easy to discredit. Any motivated social cognition that cannot be described by one of these three goals represents a damaging exception. For example, one might imagine that 
clinically depressed people frequently arrive at dinner parties preoccupied with the thought that nobody will want to speak with them. Due to their depression, they may be unmotivated to accurately understand whether there is any truth to this thought. To the contrary, they might be quite invested in believing that nobody wants to talk to them regardless of the reality of the situation. They may appear to have no desire to enhance the self as they continually make selfdeprecating remarks. In addition, they may not manifest any indications of efficient thinking; they might be willing to ruminate extensively on all the reasons why nobody likes them. Interpreted this way, this example could indeed represent an exception. However, these individuals have probably formed cohesive identities around their perception that they are disliked, not worthwhile people. Thus, their cognitions that nobody wants to talk with them do serve to maintain their sense of self, even if it is a negative sense of self.

A second set of exceptions might occur when individuals are motivated to think about a particular group towards whom they might be favorably biased. For example, athletes may be motivated to think positively about the abilities of their team prior to a competition. Although there is a technical sense in which these thoughts are not directly self enhancing, they probably serve to enhance the self indirectly. As members of the team, part of the athletes' identities and self-concepts are intertwined with the fate of the team. When team members are motivated to think positively on behalf of the team, they enhance their self-concept to the extent that they have a strong team affiliation. Even in an instance where they might be motivated to think negatively about their recent performance, these thoughts are probably motivated by a desire to bolster greater effort during the next practice or performance (thus indirectly enhancing the self via the improved team effort).

In similar vein, Asian cultures tend to be more collectivist than individualistic (Nisbett, Peng, Choi, \& Norenzayan, 2001). Members of these cultures may be less motivated to think in ways that enhance their sense of self. This research raises an important issue - the rates at which people pursue the three goals proposed here almost certainly vary across cultures. However, it still seems plausible that even if they are enhancing their sense of self less often than members of more individualistic cultures, they may still be doing so in the same indirect way that team members might be motivated to think in ways that enhance the team. Recent work that utilizes implicit measures of self-esteem provides some support for this conjecture that East Asians are still motivated to maintain a positive self-concept (Yamaguchi et al., 2007). 
As with any tentative explanation, we hope and encourage readers to contemplate other possible exceptions to have a better sense of how aptly these three tenets describe our social cognitions.

\section{Why does this formulation matter for education?}

Arguably a more important issue than potential exceptions to our conceptualization of social cognition is whether or not any practical good comes of it - what we might call the Kurt Lewin test ${ }^{1}$. Thus, this section assesses how well our formulation might facilitate our understanding of real world behaviors. Throughout this chapter we have illustrated how different mistakes that we make in social cognition might impact educational situations. This section implements our conception more holistically and illustrates how it might enhance our understanding of achievement scenarios in school settings. The first illustration explores how the goals behind our social cognitions can directly impact academic achievement; the second provides an example of indirect impact through teacher-student relationships.

\section{Direct impact}

To see the potential direct impact that the goals behind our social cognitions might have on achievement, let us turn to a typical classroom scene. During a lecture, the teacher explains a concept to the class, students listen and take notes, the teacher asks a series of questions to gauge the class's level understanding, students respond, and then the teacher decides whether to move forward or further explain the material. In these situations, teachers typically need to assess what their students are thinking, to what extent they understand the concepts in question, and what misconceptions need to be corrected before new material is introduced. In short, they are motivated to accurately understand the thoughts and comprehension level of their students. However, this is not the only goal involved in these classroom situations.

Because of the situational demands, teachers are also highly motivated to think efficiently. Taking the time to check in with each student individually as to their level of understanding would prove fatal to the overall engagement of the class. In many schools, the specter of standardized tests provides teachers with a strong extrinsic incentive to prioritize breadth over depth. Thus, teachers need to quickly sample the level of understanding of their class, hope that the sample is representative of the overall level of understanding, and make

\footnotetext{
${ }^{1}$ Lewin is quoted as saying that, "There is nothing so practical as a good theory."
} 
quick inferences about the patterns of (mis)understanding. As discussed previously, these steps that teachers take as intuitive scientists are fraught with mistakes. In spite of the likely flaws, teachers will probably develop a theory about the class's level of understanding. At the crudest level, the theory might approximate the logic that if a certain student understands, most of the class must understand. A more sophisticated theory might explain why a certain level of understanding was or was not achieved by the class as a whole or by individual students.

Once this lay theory is in place, a second set of goals will likely come into play - teachers will be motivated to find evidence that confirms their theory. To entertain evidence to the contrary might threaten their self-concept as an effective teacher. In other words, entertaining evidence to the contrary might entail acknowledging that, as a teacher, they do not have a good read on their class' level of understanding. As they continue to selectively attend to evidence that confirms their theory and ignore contradictory evidence, changing their minds will generate increasing dissonance. Thus, teachers' goal to maintain a positive sense of self can directly impede their ability to assess understanding and adapt teaching approaches to better serve their students. We suspect that the most common manifestation of this pattern is one in which teachers explain material and conclude that students understand the material. To conclude otherwise might imply that their explanation was deficient in some way. In sum, teachers' goal to accurately perceive their students' level of understanding can be derailed by their goal to assess their class' level of understanding efficiently and by their goal to maintain their sense of themselves as good teachers.

Our formulation might also explain achievement-related student behavior throughout this same scenario. As teachers explain new concepts in their class, a primary student goal might be attempting to accurately assess what their teachers think they should know. In other words, students need to parse apart important information (i.e., signal) from that which is superfluous (i.e., noise). As they begin their intuitive scientist processes of collecting clues and developing theories, they will assess as efficiently as possible which information their teacher values. They have no choice but to make these assessments efficient; as they assess, students must simultaneously understand the actual concepts which are being conveyed. Once a theory perhaps that what the teacher writes on the board is the valued information - is in place, they too will likely look to confirm their theory. We suspect that just about every teacher has been on the receiving end of students seeking to test their theory with a version of the "Will this be on the 
test?” question. Once students have a lay theory about which information their teacher values, they will be motivated to selectively interpret new evidence as supporting their theory. Often students are later confronted with problematic evidence in the form of a poor test performance. In this case, they could acknowledge that their theory of what their teacher values is flawed. However, this admission is tantamount to admitting that they lack sav. It may well be easier to decide that the test was unfair, the teacher is biased, or some other rationalization that would preserve the students' sense of self.

Other illustrations abound as to how these goals interact to explain the impact of classroom-based social interchanges on achievement. Students' refusal to see flaws in a paper may represent their goal to maintain a positive sense of self overriding their goal to accurately understand their teacher's feedback. Teachers determining which information to include in a lesson plan may illustrate competition between two goals: accurately assessing what students need to know in today's world versus efficiently deciding on content by anchoring with what they were taught at that age and adjusting from there. However, we suspect that the indirect impact of these goals might be even more important in their role in explaining student achievement.

\section{Indirect impact}

Numerous social aspects of the classroom may indirectly impact student achievement. In this section, we focus on teacher-student relationships as a particularly important example. This indirect influence on student achievement can be impeded or bolstered by the three goals we have proposed. In particular, we highlight the potential biases and errors in social cognition that can affect these relationships.

Educational settings are inherently social worlds. In order to teach or to learn, students and teachers must have dozens of daily interactions that ultimately lead to the development of relationships. Positive teacher-student relationships play an important role in the development of school competencies, such as attention, motivation, problem-solving, and self-esteem (Birch \& Ladd, 1997; Pianta \& Walsh, 1996). Furthermore, relationships with adults impact children's emotional development, self-regulation (Denham \& Burton, 1996) and peer relations (Elicker, Englund, \& Sroufe, 1992; Howes, Matheson, \& Hamilton, 1994). The quality of teacher-student relationships are also associated with students’ grade point averages (DiLalla, Marcus, \& Wright-Phillips, 2004). These relationships can have lasting impacts on academic achievement. 
Hamre and Pianta (2001) found that negativity in teacher-child relationships in kindergarten uniquely predicted students' grades, standardized test scores, and work habits through lower elementary school, even after controlling for characteristics such as gender, ethnicity, and cognitive ability.

Upon reflecting on one's personal experiences in school, it may be easy to understand why teacher-child relationships affect academic achievement so much. Many adults may remember how a close bond with a favorite teacher acted as powerful motivator to try harder in that class. Many more adults probably recall their least favorite teacher, who may have been an even more powerful de-motivator. Beyond motivation, teacher-student relationship quality may reflect the extent to which students engage the available instructional resources in the classroom (Entwisle \& Hayduk, 1988).

If teachers want to motivate and support learning for their students, then why do some teachers fail to develop close relationships while others succeed? We suggest that part of the variability in these relationships can be attributed to the three goals that underlie social cognitions. To illustrate how these goals might play out in the realm of teacher-child relationships, imagine a teacher who pays particular attention to getting to know his students at the beginning of every year. He observes his students, identifies patterns of behavior, and develops predictions about different children.

These "intuitive scientist" activities that the teacher engages in are essential first steps to developing relationships with his students. As we stated earlier, accurate inferences and predictions should lead to more effective behaviors. In general, the more accurate the teacher's inferences are about various students, the better his relationships with them should be. By clearly understanding their thoughts, feelings, and motivations, he can provide appropriate, individualized support that should contribute not only to improving their relationship, but also to increasing their achievement.

Unfortunately, his goal to accurately perceive his students may be affected by his goal to be seen in a flattering light. In school settings, teachers are pressured to ensure that students meet the standards of their parents, school, community, and government. In this pressured environment, a teacher's tendency to enhance the self may be heightened. The teacher's goal to enhance or maintain his self-concept is not necessarily bad for his relationships with students. For instance, when students repeatedly disrupt class, the teacher may sit down and patiently try 
to discover the cause of the behavior in order to maintain his identity as a caring teacher (and to be perceived as caring by others).

However, in a pressured educational climate, the need for efficiency may interact with the need to enhance his sense of self. The teacher might instead speak briefly with the students to get the "problem children” under control. Viewing a subset of his classroom as having dispositional defects involves little cognitive effort and avoids the suggestion that the disruptive behavior could be the result of his poor classroom management. Due to a self-serving bias, the teacher might believe that he spent more time talking to these students than the average teacher would. Thanks to naïve realism, he may perceive that any reasonable person would see how patient he had been. Thus, if the students react with anything less than gratitude, the frustrations will begin to flow. Each time that more problems emerge, it will confirm the teacher's conclusion about this group of students. As his stereotype of these students solidifies, the representativeness heuristic may play an important role in generalizing the teacher's view of these students from "behavior problems" to "bad students”. Expectations of these students' academic work might decline and negative self-fulfilling prophecies may begin. Meanwhile, the students’ perceptions of their teacher's view of them may lead to lower self-esteem, decreased interest and effort in school, or more acting out.

In this way, the interplay of the goals behind the teacher's cognitions can powerfully impact his relationships with students which, in turn, may impact their achievement. Ironically, high quality teacher-child relationships are even more important for "at-risk" and insecurely attached children, who may also require the most effort to understand (Ainsworth, 1989; Birch \& Ladd, 1997; Burchinal, Peisner-Feinberg, Pianta, \& Howes, 2002).

The conceptualization put forth in this chapter offers a new lens through which teacherstudent relationship formation can be viewed. The fundamental goal to perceive our social worlds accurately acts as a catalyst for these relationships. However, the errors and ulterior goals of our social cognitions may impede the development of positive student-teacher relationships and, in turn, student achievement.

\section{Social perspective taking}

Although we have focused largely on the mistakes that we make as social perceivers and the trouble that these three basic goals can get us into, we would like to conclude on a positive note. The functionality of our social cognitions and the goals that direct them is generally quite 
impressive. Assessing the mental worlds of others hundreds of times a day as we often do is a daunting task. Yet, we tend to carry it off with surprising efficiency and accuracy. Because this assessment task is so critical to navigating our social environments we might hope that schools would help facilitate students’ motivation and ability to accurately perceive their social environments while minimizing biases that emerge through the goals to think efficiently and to enhance the self.

The work on social perspective taking (SPT) appears promising in this regard. SPT consists of discerning the thoughts and feelings of others; it often requires that we determine how others perceive the social situation. It encompasses both an ability that can result in accurate or inaccurate assessments as well as a propensity to engage this ability; that is, individuals may tend to take the perspective of others more or less frequently (Gehlbach, 2004a). Research has shown SPT to be associated with altruistic behavior (Batson, Early, \& Salvarani, 1997), a reduction in stereotypic thinking and in-group bias (Galinsky \& Moskowitz, 2000), and fostering cooperation between students (Johnson, 1975).

Through these types of outcomes SPT should facilitate learning by improving teachers’ and students' interpersonal relationships and their perceptions of the classroom climate. Teachers who are accurate and motivated perspective takers will be more likely to avoid the traps of naïve realism. SPT may help students to balance their goal of maintaining their sense of self to think about the good of the larger community in addition. Because SPT has also been associated with academic achievement (Gehlbach, 2004b), a more direct relationship to achievement is also possible. Students who more accurately and/or more frequently try to understand how different classmates are thinking about and reacting to the material would seem poised to develop a richer understanding of the curriculum.

Incorporating the teaching of this aptitude into different curricula could be tremendously valuable, particularly in social studies or literature classes where there is often a need to understand the thoughts and feelings of people from different cultures and historical periods. With the potential to impact achievement directly and indirectly, through interpersonal relationships, interventions that incorporate this aptitude into the curriculum seem doubly promising. We also see great potential to impact student achievement by incorporating SPT into teacher preparation. As research in this area continues, we hope that scholars will develop 
increasingly effective, concrete strategies and approaches to teaching this important aptitude as a means to counteracting some of the biases in our social thinking. 


\section{References}

Ainsworth, M. S. (1989). Attachments beyond infancy. American Psychologist, 44(4), 709-716.

Allport, G. W. (1979/1954). The nature of prejudice (Unabridged, 25th anniversary ed.). Reading, Mass.: Addison-Wesley Pub. Co.

Ambady, N., \& Rosenthal, R. (1993). Half a minute: Predicting teacher evaluations from thin slices of nonverbal behavior and physical attractiveness. Journal of Personality and Social Psychology, 64(3), 431-441.

Ames, D. (2004). Inside the mind-reader's toolkit: Projection and stereotyping in mental state inference. Journal of Personality and Social Psychology, 87(3), 340-353.

Arkin, R. M., Appelman, A. J., \& Burger, J. M. (1980). Social anxiety, self-presentation, and the self-serving bias in causal attribution. Journal of personality and social psychology, 38(1), 23-35.

Batson, C. D., Early, S., \& Salvarani, G. (1997). Perspective taking: Imagining how another feels versus imagining how you would feel. Personality and Social Psychology Bulletin, 23(7), 751-758.

Beaman, R., Wheldall, K., \& Kemp, C. (2006). Differential teacher attention to boys and girls in the classroom. Educational Review, 58(3), 339-366.

Birch, S. H., \& Ladd, G. W. (1997). The teacher-child relationship and children's early school adjustment. Journal of School Psychology, 35(1), 61-79.

Burchinal, M. R., Peisner-Feinberg, E., Pianta, R., \& Howes, C. (2002). Development of Academic Skills from Preschool Through Second Grade: Family and Classroom Predictors of Developmental Trajectories. Journal of School Psychology, 40(5), 415-436.

Chapman, L. J. (1967). Illusory correlation in observational report. Journal of Verbal Learning \& Verbal Behavior, 6(1), 151-155.

Cialdini, R. B. (2001). Influence: Science and practice (4th ed.). Boston, MA: Allyn and Bacon.

Cooper, J., \& Fazio, R. H. (1984). A new look at dissonance theory. In L. Berkowitz (Ed.), Advances in experimental social psychology (Vol. 17, pp. 229-266): Academic Press.

Denham, S. A., \& Burton, R. (1996). A social-emotional intervention for at-risk 4-year-olds. Journal of School Psychology, 34(3), 225-245.

Devine, P. (1995). Prejudice and out-group perception. In A. Tesser (Ed.), Advanced social psychology (pp. 466-524). New York: McGraw-Hill. 
Dijksterhuis, A., van Knippenberg, A., Kruglanski, A. W., \& Schaper, C. (1996). Motivated social cognition: Need for closure effects on memory and judgment. Journal of Experimental Social Psychology, 32(3), 254-270.

DiLalla, L. F., Marcus, J. L., \& Wright-Phillips, M. V. (2004). Longitudinal effects of preschool behavioral styles on early adolescent school performance. Journal of School Psychology, 42(5), 385-401.

Dunning, D. (1999). A newer look: Motivated social cognition and the schematic representation of social concepts. Psychological Inquiry, 10(1), 1.

Elicker, J., Englund, M., \& Sroufe, L. A. (1992). Predicting peer competence and peer relationships in childhood from early parent-child relationships. In R. D. Parke \& G. W. Ladd (Eds.), Family-peer relationships: Modes of linkage. (pp. 77-106): Lawrence Erlbaum Associates, Inc.

Entwisle, D. R., \& Hayduk, L. A. (1988). Lasting effects of elementary school. Sociology of Education, 61(3), 147-159.

Epley, N., Keysar, B., Van Boven, L., \& Gilovich, T. (2004). Perspective taking as egocentric anchoring and adjustment. Journal of Personality and Social Psychology, 87(3), 327-339.

Erikson, E. H. (1968). Identity, youth, and crisis (1st ed.). New York,: W. W. Norton.

Festinger, L. (1962). Cognitive dissonance. Scientific American, 207(4), 93-107.

Fine, M. (1991). Framing dropouts: Notes on the politics of an urban public high school. Albany, N.Y.: State University of New York Press.

Fiske, S. T. (1995). Social cognition. In A. Tesser (Ed.), Advanced social psychology (pp. 145194). New York: McGraw-Hill.

Galinsky, A. D., \& Moskowitz, G. B. (2000). Perspective-taking: Decreasing stereotype expression, stereotype accessibility, and in-group favoritism. Journal of Personality and Social Psychology, 78(4), 708-724.

Gehlbach, H. (2004a). A new perspective on perspective taking: A multidimensional approach to conceptualizing an aptitude. Educational Psychology Review, 16(3), 207-234.

Gehlbach, H. (2004b). Social perspective taking: A facilitating aptitude for conflict resolution, historical empathy, and social studies achievement. Theory and Research in Social Education, 32(1), 39-55. 
Greenberg, J., Pyszczynski, T., Burling, J., \& Tibbs, K. (1992). Depression, self-focused attention, and the self-serving attributional bias. Personality and Individual Differences, 13(9), 959-965.

Hamre, B. K., \& Pianta, R. C. (2001). Early teacher-child relationships and the trajectory of children's school outcomes through eighth grade. Child Development, 72(2), 625-638.

Heider, F. (1958a). Perceiving the other person. In R. Tagiuri \& L. Petrullo (Eds.), Person perception and interpersonal behavior (pp. 22-26). Stanford: Stanford University Press.

Heider, F. (1958b). The psychology of interpersonal relations. Mahwah, NJ: Lawrence Erlbaum Associates Publishers.

Howes, C., Matheson, C. C., \& Hamilton, C. E. (1994). Maternal, teacher, and child care history correlates of children's relationships with peers. Child development, 65(1), 264-273.

Johnson, D. W. (1975). Cooperativeness and social perspective taking. Journal of Personality and Social Psychology, 31, 241-244.

Jussim, L., \& Eccles, J. S. (1992). Teacher expectations: II. Construction and reflection of student achievement. Journal of personality and social psychology, 63(6), 947-961.

Katz, D., \& Braly, K. (1933). Racial stereotypes of one hundred college students. The Journal of Abnormal and Social Psychology, 28(3), 280-290.

Kruger, J. (1999). Lake Wobegon be gone! The 'below-average effect' and the egocentric nature of comparative ability judgments. Journal of Personality and Social Psychology, 77(2), 221-232.

Kunda, Z. (1990). The case for motivated reasoning. Psychological Bulletin, 108(3), 480-498.

Loewen, J. W. (1995). Lies my teacher told me: Everything your American history textbook got wrong. New York: New Press.

Nisbett, R. E., Peng, K., Choi, I., \& Norenzayan, A. (2001). Culture and systems of thought: Holistic versus analytic cognition. Psychological Review, 108(2), 291-310.

Perkins, D. N., Tishman, S., Ritchhart, R., Donis, K., \& Andrade, A. (2000). Intelligence in the wild: A dispositional view of intellectual traits. Educational Psychology Review, 12(3), 269-293.

Pianta, R. C., \& Walsh, D. J. (1996). High-risk children in schools: Constructing sustaining relationships. New York: Routledge. 
Rosenthal, R. (2002). The Pygmalion effect and its mediating mechanisms. In J. Aronson (Ed.), Improving academic achievement: Impact of psychological factors on education (pp. 321). San Diego, CA, US: Academic Press.

Rosenthal, R., \& Jacobson, L. (1968). Pygmalion in the classroom; teacher expectation and pupils' intellectual development. New York,: Holt Rinehart and Winston.

Ross, L. (1981). The "intuitive scientist" formulation and its developmental implications. In J. H. Flavell \& L. Ross (Eds.), Social cognitive development: Frontiers and possible futures (pp. 1-42). Cambridge: Cambridge University Press.

Ross, L., Amabile, T. M., \& Steinmetz, J. L. (1977). Social roles, social control, and biases in social-perception processes. Journal of Personality and Social Psychology, 35(7), 485494.

Ross, L., Greene, D., \& House, P. (1977). The false consensus effect: An egocentric bias in social perception and attribution processes. Journal of Experimental Social Psychology, 13(3), 279-301.

Ross, L., \& Ward, A. (1996). Naive realism in everyday life: Implications for social conflict and misunderstanding. In E. S. Reed \& E. Turiel (Eds.), Values and knowledge (pp. 103-135). Mahwah: Lawrence Erlbaum Associates Inc.

Sherif, M., Harvey, O. J., White, B. J., Hood, W., \& Sherif, C. (1961). Intergroup conflict and cooperation; the Robbers Cave experiment. Norman: University of Oklahoma. Institute of Intergroup Relations.

Turner, J. C., Brown, R. J., \& Tajfel, H. (1979). Social comparison and group interest ingroup favouritism. European Journal of Social Psychology, 9(2), 187-204.

Tversky, A., \& Kahneman, D. (1974). Judgment under uncertainty: Heuristics and biases. Science, 185(4157), 1124-1131.

Wason, P. C. (1960). On the failure to eliminate hypotheses in a conceptual task. The Quarterly Journal of Experimental Psychology, 12, 129-140.

Waterman, A. S. (1982). Identity development from adolescence to adulthood: An extension of theory and a review of research. Developmental psychology, 18(3), 341-358.

Yamaguchi, S., Greenwald, A. G., Banaji, M. R., Murakami, F., Chen, D., Shiomura, K., et al. (2007). Apparent universality of positive implicit self-esteem. Psychological Science, 18(6), 498-500. 
Zajonc, R. B. (1980). Feeling and thinking: Preferences need no inferences. American Psychologist, 35(2), 151-175. 